\title{
Clinical implications of cytogenetic and molecular aberrations in multiple myeloma
}

\author{
Sarah Goldman-Mazur ${ }^{1}$, David H. Vesole ${ }^{2}$, Artur Jurczyszyn ${ }^{1 *}$ \\ ${ }^{1}$ Department of Haematology, Jagiellonian University Medical College, Krakow, Poland \\ ${ }^{2}$ The John Theurer Cancer Centre at Hackensack UMC, Hackensack, New York, USA
}

\begin{abstract}
Multiple myeloma (MM) is an incurable haematological malignancy affecting approximately 7:100,000 people. Monoclonal gammopathy of undetermined significance (MGUS) and 'smouldering' MM precede symptomatic MM. Cytogenetics in MM is the most powerful prognostication tool incorporated into different classifications, including the Revised International Staging System (R-ISS) and the Mayo Clinic Risk Stratification for Multiple Myeloma (mSMART). Methods commonly used to test for cytogenetic aberrations include conventional karyotyping and fluorescence in situ hybridisation (FISH), although the difficulty of obtaining metaphases in plasma cells results in low yields.

Therefore, new genomic tools are essential to explore the complex landscape of genetic alterations in MM. These include next generation sequencing, a highly sensitive method to monitor minimal residual disease. The serial evolution of MGUS to MM is accompanied by a range of heterogenous genetic abnormalities, divided into primary (involving mostly chromosome 14 translocations and trisomies) and secondary genetic aberration events (involving mostly 17p, 1p, 13q deletions, 1q gain, or MYC translocations). Based on the primary genetic aberration results, strong prognostic features of MM have been identified with distinct clinical characteristics. High risk aberrations include $17 \mathrm{p}$ deletion, $\mathrm{t}(4 ; 14)$, $t(14 ; 16), t(14 ; 20)$ and chromosome 1 abnormalities. The incorporation of novel drugs and maintenance strategies in conjunction with autologous stem cell transplantation partially overcome the adverse effect of some of these genetic aberrations. Nonetheless, survival remains worse in this group compared to standard risk patients. Clinical decisions regarding treatment should be based on the cytogenetic results. The establishment of individualised and mutation-targeted therapies are of the greatest importance in future studies.
\end{abstract}

Key words: myeloma, cytogenetics, prognosis, high risk, genomics, aberration

Acta Haematologica Polonica 2021; 52, 1: 18-28

\section{Introduction}

Multiple myeloma (MM) is a neoplastic plasma cell disorder which affects approximately seven in every 100,000 people, giving it the second highest incidence among all haematological malignancies in the Western world [1-3]. $\mathrm{MM}$ is preceded by a pre-malignant stage called monocIonal gammopathy of undetermined significance (MGUS), which is present in over $3 \%$ of the population $>50$-years-old, and the incidence increases with age [4]. The risk of progression of MGUS to MM is approximately $1 \%$ per year depending on prognostic features (e.g. paraprotein concentration, immunoglobulin isotype and free light chain ratio) [5]. While MGUS is a 'benign precursor state' which is devoid of any myeloma defining events (MDE), MM can cause severe symptoms and end-stage organ damage including renal insufficiency (present in $20 \%$ of newly diagnosed patients), anaemia (haemoglobin $<12 \mathrm{~g} / \mathrm{dL}$ present in $73 \%$ of patients), skeletal lesions (present in approximately $65-75 \%$ of patients) or hypercalcemia (calcium level $>11 \mathrm{mg} / \mathrm{dL}$ present in $13 \%$ of patients) [6]. According to the updated International Myeloma Working
*Address for correspondence: Artur Jurczyszyn, Department

of Haematology, University Hospital in Cracow, 17 Kopernika,

31-501 Krakow, Poland, phone: +48 1242476 00,

fax: +48 1242476 26, e-mail: mmjurczy@cyf-kr.edu.pl

Received: 27.08 .2020

Accepted: 14.11.2020
PTHiT Copyright $\odot 2021$

The Polish Society of Haematologists and Transfusiologists,

Insitute of Haematology and Transfusion Medicine.

All rights reserved. 
Table I. For diagnosis of multiple myeloma, the criterium of clonal bone marrow plasma cells $\geq 10 \%$ or biopsy-proven bony or extramedullary plasmacytoma should be met, and any one or more of the following myeloma-defining events (SLiM CRAB) should be present

\begin{tabular}{|c|c|}
\hline Calcium & $\begin{array}{l}\text { Hypercalcemia: serum calcium }>0.25 \mathrm{mmol} / \mathrm{L}(>1 \mathrm{mg} / \mathrm{dL} \text { ) higher than upper limit of normal or }>2.75 \mathrm{mmol} / \mathrm{L} \\
(>11 \mathrm{mg} / \mathrm{dL})\end{array}$ \\
\hline Renal Insufficiency & Renal insufficiency: creatinine clearance $<40 \mathrm{~mL}$ per minute or serum creatinine $>177 \mu \mathrm{mol} / \mathrm{L}(>2 \mathrm{mg} / \mathrm{dL}$ ) \\
\hline Anaemia & Anaemia: haemoglobin value of $>2 \mathrm{~g} / \mathrm{dL}$ below lower limit of normal, or haemoglobin value $<10 \mathrm{~g} / \mathrm{dL}$ \\
\hline Bones & $\begin{array}{l}\text { Bone lesions: one or more osteolytic lesions on skeletal radiography, computed tomography (CT), or positron } \\
\text { emission tomography-CT (PET-CT) }\end{array}$ \\
\hline Sixty & Clonal bone marrow plasma cell percentage $\geq 60 \%$ \\
\hline Light chains & Involved: uninvolved serum free light chain $(\mathrm{FLC})$ ratio $\geq 100$ (involved free light chain level must be $\geq 100 \mathrm{mg} / \mathrm{L}$ ) \\
\hline Magnetic resonance & sion on magnetic resonance imaging (MRI) studies (at least 5 mm in size) \\
\hline
\end{tabular}

Group (IMWG) criteria, the diagnosis requires $\geq 10 \%$ clonal bone marrow plasma cells or a biopsy-proven plasmacytoma plus evidence of one or more MDE included in the SLiM-CRAB acronym (Table I) [7]. However, unlike other haematological malignancies, no specific cytogenetic pathognomonic criterium for MM exists.

The disease is considered incurable, and survival may vary from a few months to over 15 years; this diversity is most strongly driven by the genetic abnormalities present in the plasma cells [8].

In the era of modern drugs including proteasome inhibitors (PIs) (bortezomib/carfilzomib/ixazomib), immunomodulatory drugs (IMIDs) (thalidomide/lenalidomide/pomalidomide), monoclonal antibodies (daratumumab/isatuximab/ /elotuzumab), and antibody drug conjugates (belantamab mafodotin), median overall survival reaches $6+$ years [9].

Several features affect survival: host characteristics, tumour burden and biology (cytogenetics) as well as the response to treatment. Laboratory risk factors for a poorer prognosis have been identified, including serum beta b $_{2}$-microglobulin ( $\beta 2 \mathrm{M})$, low albumin and/or elevated lactate dehydrogenase. However, genetic changes seem to play the largest role in prognosis in MM [10].

Studying myeloma genetics has been always limited due to low proliferation potential of the plasma cells for standard karyotype analysis. Nonetheless, in recent years the development of genetic tools including microarrays and next-generation sequencing (NGS) has led to substantial progress in understanding the genetics of MM [11].

MM remains a highly heterogenous and complex disease with varied genetic aberrations resulting in multiple subclones. A major clone dominates throughout the disease course, although minor clones may evolve and be responsible for chemoresistance or serve as a reservoir for relapses or progressions [11, 12]. Interestingly, in a recent study by Merz et al., the presence of subclones was prognostic for smouldering MM to transform into MM; however, the risk of progression was not constant and changed due to clonal evolution [13]. Nonetheless, the mechanism and driving factors resulting in the development of how these subclones emerge, how they are selected and what is their prognostic implication, need to be investigated in future studies.

In general, the pathogenesis of MM can be visualised by two steps: the establishment of MGUS and progression from MGUS to MM (Figure 1) [14]. This process is accompanied by different cytogenetic changes (Table II). The evolution of MGUS is thought to be a result of abnormal antigen stimulation and is caused by primary cytogenetic aberration events, so-called 'disease-initiating' aberrations. The primary cytogenetic abnormalities help to classify MGUS and MM into several subtypes and consist mostly of trisomies and translocations involving chromosome 14 [5]. Additionally, primary cytogenetic abnormalities are mostly non-overlapping [15]. The second step occurs rather due to random cytogenetic mutations (called secondary cytogenetic aberration events) resulting in the evolution to symptomatic MM and further MM progression [16]. Secondary cytogenetic aberrations might overlap, and are typically subclonal (Figure 1) [5].

This review provides an overview of the different cytogenetic approaches used to stratify MM patients. We will discuss cytogenetic and molecular aberrations, their frequency, and clinical and prognostic implications.

\section{Laboratory testing strategy}

\section{Conventional cytogenetics (G-band karyotyping)}

Conventional cytogenetics is a well-established and universally available test, and it also provides a whole genome analysis at once. On the other hand, the detection of chromosomal abnormalities using conventional cytogenetics is limited due to low proliferative activity of malignant plasma cells and low number of plasma cells in an often haemodiluted bone marrow aspirate. Chromosomal abnormalities are detected in only $30 \%$ of patients without $\mathrm{CD} 138^{+}$cell enrichment [17]. In plasma cell leukemia, cytogenetic aberrations are more common (up to $68 \%$ of cases) [18]. Despite this limitation, karyotyping provides essential 


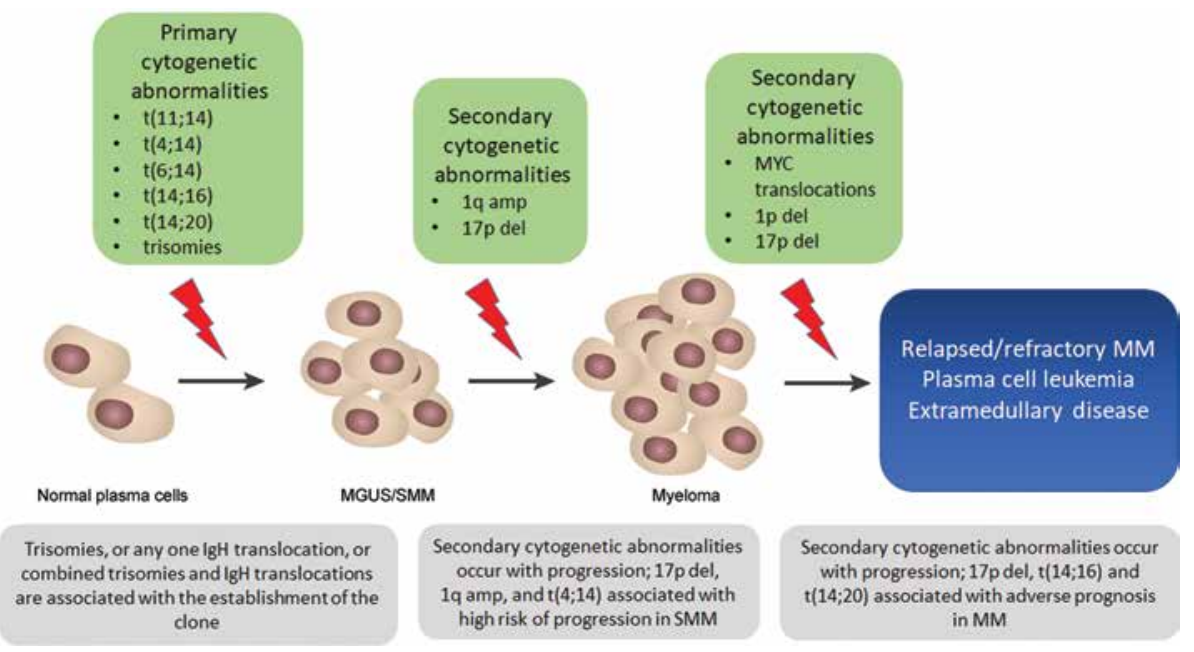

Figure 1. Cytogenetic abnormalities in multiple myeloma (MM) (modified from [14]); amp - amplification; del - deletion; IgH - immunoglobulin heavy chain; MGUS - monoclonal gammopathy of undetermined significance; SMM - smoldering multiple myeloma; $\mathrm{t}$ - translocation

Table II. Genetic abnormalities in multiple myeloma, their frequency and clinical impact

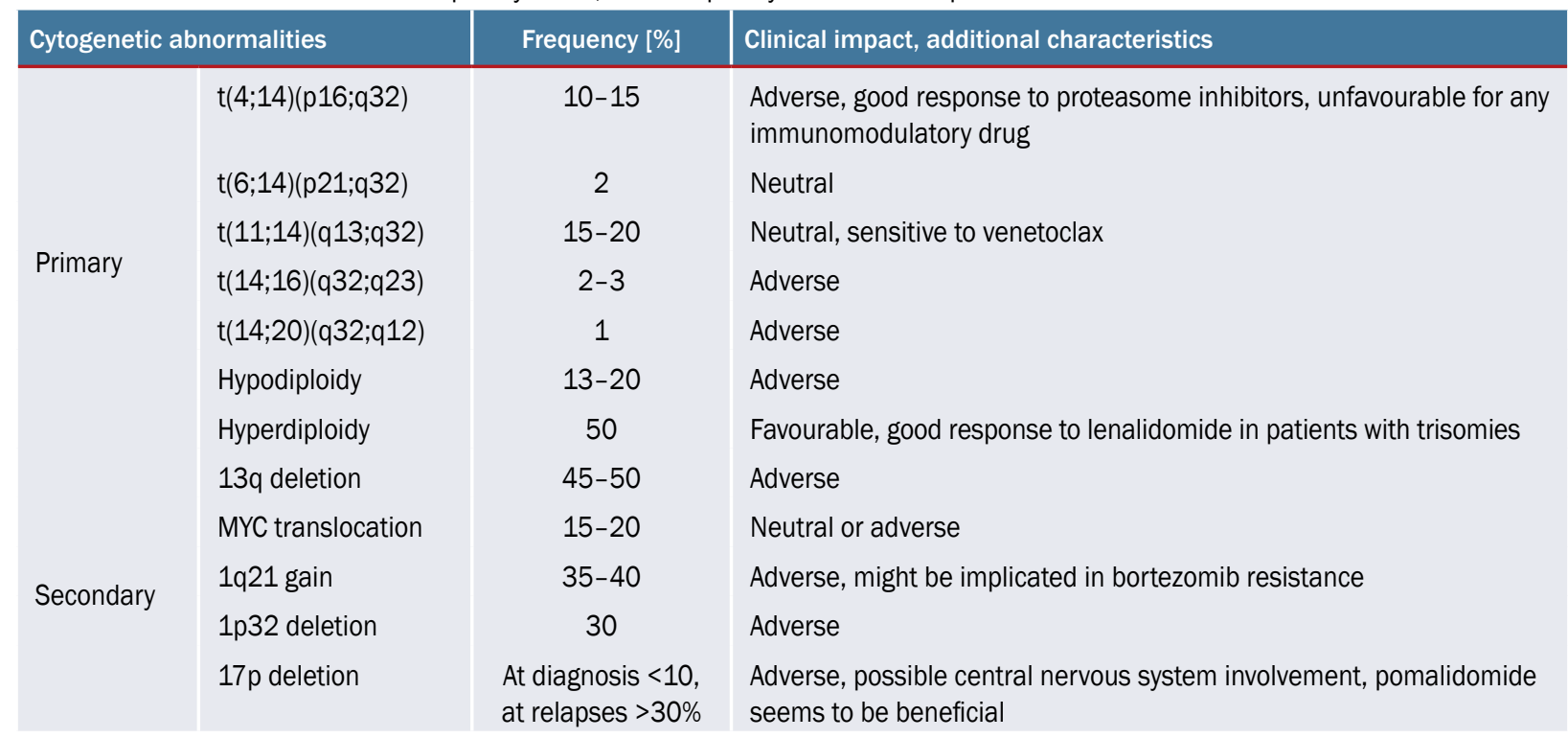

information on numerical and structural chromosomal changes. Numerical aberrations include hyperdiploidy or non-hyperdiploidy, whereas structural abnormalities include translocations or copy number aberrations (i.e. deletions or gains). Furthermore, conventional karyotyping is an independent prognostic factor even in the era of modern testing modalities [e.g. fluorescence in situ hybridisation (FISH), NGS, and gene-expression profiling (GEP)], and should be routinely performed as an initial diagnostic workup especially in situations where a FISH test is unavailable [19, 20].

\section{FISH analysis}

FISH testing is based on the use of fluorescent probes that bind to highly complementary nucleic acid sequence. Using a variety of FISH probes, numerous genetic alterations might be detected, including numerical amplifications or deletions, structural rearrangements and translocations [21]. On conventional cytogenetics, in patients with complex karyotype, some aberrations (e.g. translocations) are cryptic, and FISH enables their detection [22]. Furthermore, a FISH test does not depend on the proliferation rate, and the probes can be applied on nondividing cells, mainly on interphase cells [21]. However, the detection sensitivity is limited by the number of plasma cells in the whole bone marrow, which is especially low in patients after treatment or early in the diagnosis or relapse (when plasma cells range from 1-20\%) [23]. Consequently, FISH is run mainly on CD138 ${ }^{+}$enriched cells, and different techniques are used to target and enrich the monoclonal plasma cells, e.g. immunostaining (cytoplasmic immunoglobulin FISH, clg-FISH), 
Table III. Staging strategies in multiple myeloma according to different working groups

\begin{tabular}{|c|c|c|}
\hline $\begin{array}{l}\text { Staging sy- } \\
\text { stem }\end{array}$ & Stage & Criteria \\
\hline \multirow{3}{*}{$\begin{array}{l}\text { International } \\
\text { Staging Sy- } \\
\text { stem (ISS) }\end{array}$} & Stage I & $\begin{array}{l}\beta 2 \mathrm{M}<3.5 \mathrm{mg} / \mathrm{dL} \text { and albumin } \\
\geq 3.5 \mathrm{~g} / \mathrm{dL}\end{array}$ \\
\hline & Stage II & Neither I nor III \\
\hline & Stage III & $\beta 2 \mathrm{M} \geq 5.5 \mathrm{mg} / \mathrm{dL}$ \\
\hline \multirow{3}{*}{$\begin{array}{l}\text { Revised } \\
\text { International } \\
\text { Staging Sy- } \\
\text { stem (R-ISS) }\end{array}$} & Stage I & $\begin{array}{l}\text { ISS I, standard risk by FISH (no } \\
\text { high-risk chromosomal abnor- } \\
\text { malities) and normal LDH }\end{array}$ \\
\hline & Stage II & Neither R-ISS I nor III \\
\hline & Stage III & $\begin{array}{l}\text { ISS III, either high risk by FISH } \\
\text { [del(17p) and/or } \mathrm{t}(4 ; 14) \text { and/or } \\
\mathrm{t}(14 ; 16)] \text { or high LDH (> upper } \\
\text { limit of normal) }\end{array}$ \\
\hline \multirow{12}{*}{$\begin{array}{l}\text { Mayo Clinic } \\
\text { Risk Stra- } \\
\text { tification } \\
\text { for Multiple } \\
\text { Myeloma } \\
\text { (mSMART) }\end{array}$} & Stan- & Trisomies \\
\hline & $\begin{array}{l}\text { dard } \\
\text { risk }\end{array}$ & $\begin{array}{l}t(11 ; 14) \\
t(6 ; 14)\end{array}$ \\
\hline & High & $\mathrm{t}(4 ; 14)$ \\
\hline & & $t(14: 16)$ \\
\hline & & $t(14 ; 20)$ \\
\hline & & $17 p$ deletion \\
\hline & & 1q gain \\
\hline & & R-ISS stage III \\
\hline & & $\begin{array}{l}\text { High plasma cell S-phase (cut-off } \\
\text { varies) }\end{array}$ \\
\hline & & GEP: high risk signature \\
\hline & & $\begin{array}{l}\text { Double-hit: any two high-risk } \\
\text { factors }\end{array}$ \\
\hline & & $\begin{array}{l}\text { Triple-hit: any three or more high- } \\
\text {-risk factors }\end{array}$ \\
\hline $\begin{array}{l}\text { Gene-expres- } \\
\text { sion-based } \\
\text { signatures }\end{array}$ & & $\begin{array}{l}\text { Presence of alterations detected } \\
\text { by: UAMS, Skyline 92-HOVON, } \\
\text { IFM }\end{array}$ \\
\hline
\end{tabular}

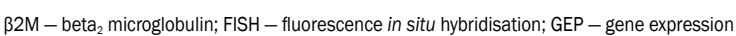
profiling; LDH - lactate dehydrogenase

selection by magnetic cell sorting (MACS), fluorescence-activated cell sorting (FACS), as well as targeted manual scoring or customised automated image analysis [24].

The European Myeloma Network (EMN) guidelines recommend that at least 100 cells should be scored when analysing FISH [23]. The cut-off value for positivity remains a controversial issue and varies from laboratory to laboratory; there is no uniform criterion. It is related to the testing strategy and the various ways to establish cut-off for different FISH patterns in different laboratories [25, 26]. It is recommended by the EMN to use conservative cut-off levels: $10 \%$ for fusion or break-apart probes and $20 \%$ for numerical abnormalities [23], although in clinical practice the threshold for a positive test is very often much lower.

\section{Molecular methods}

Although not used in daily clinical practice outside clinical trials, advanced oncogenomic analyses are very important tools to understand the complex genetic landscape, and hence clinical outcomes, of MM patients. Different genomic analysis methods exist to research into the various processes of translating the genomic information. The most comprehensive test, NGS, is a process that allows the determination of the sequence of nucleotides in a section of DNA. This provides a full, integrated spectrum of gene mutations, aneuploidies, segmental copy-number changes and translocations. Utilising NGS has identified several recurrent gene mutations in newly diagnosed MM patients, including the most common mitogen activated protein $\mathrm{ki}$ nase (MAPK) pathway, NF-kB pathway and TP53 pathway genes [27]. Although NGS is not yet universally available, in the future it will be an important tool in the diagnosis and monitoring of the minimal residual disease (MRD) due to its high sensitivity [28]. Of note, large sequencing studies in $\mathrm{MM}$ are being conducted to determine the relevance of different mutations, and preliminary results are promising (CoMMpass, The Myeloma Genome Project) [29, 30]. The GEP analyses the RNA expression of different genes pertinent to different functions [31]. It is an important marker to detect high risk patients (Table III) [32], and it also helps to establish classifiers for prognostication in addition to the International Staging System (ISS) or FISH known high risk factors [33]. Several genes lists have been found to have strong prognostic information, including commercially available GEP70 and SKY92 profiles [32, 34]. A single-nucleotide polymorphism (SNP)-microarray is a technique of the hybridisation of fragmented single-stranded DNA to arrays containing hundreds of thousands of unique nucleotide probe sequences. SNP is the smallest genetic variation that can occur within a DNA sequence. SNP microarray can detect small copy number changes such as gene deletion, chromothripsis, complex copy number changes, and amplification, as well as copy neutral loss of heterozygosity (CN-LOH), which is an important oncogenic event [25]. It also detects aberrations in small populations (subclones) due to clonal evolution [25], of which the most common are complex MYC 8q24 rearrangements or amplifications, $1 q$ gain, $1 p$ and $17 p$ deletions [35, 36].

Using the genomic tools, several molecular classifications have been established in MM. They have been also incorporated into well-known staging systems to more precisely estimate an individual patient's disease risk and clinical outcome. Incorporating the novel molecular methods into clinical use and establishing personalised therapies based on the molecular findings will be of the utmost urgency. 


\section{Cytogenetic abnormalities}

\section{Primary cytogenetic abnormalities \\ Hyperdiploidy}

Hyperdiploidy, commonly involving gain of odd-numbered chromosomes (trisomies), is detected in approximately $50 \%$ of patients with MM $[5,37]$. Trisomies 3 and 5 are known to improve overall survival, but trisomy 21 impairs overall survival [38]. Patients with trisomies have particularly good response to IMIDs [39]. In approximately 10\% of patients, trisomies and IgH translocations coexist [37]. The prognostic impact of this coexistence is a matter of controversy. Kumar et al. reported the presence of trisomies in patients with high risk translocations, namely $\mathrm{t}(4 ; 14)$, $t(14 ; 16), t(14 ; 20)$, or TP53 deletion, treated with modern drugs (PI and IMiD- based regimens). The adverse impact associated with these prognostic markers was partially ameliorated [37]. In contrast, Pawlyn et al. showed that in high risk cytogenetic patients coexistent hyperdiploidy did not abrogate a poor prognosis, although the patients were treated with older conventional drugs (cyclophosphamide with thalidomide and dexamethasone, or with vincristine) [40]. Hyperdiploidy is often accompanied by other structural chromosome changes (e.g. translocations, deletions or duplications) and a hyperdiploid karyotype with $\geq 2$ of those aberrations should be considered as an independent high risk factor [41].

\section{Non-hyperdiploidy}

Non-hyperdiploidy is defined as hypodiploid, pseudodiploid, and near-tetraploid karyotypes. Hypodiploidy is defined as having $\leq 44$ chromosomes in a cell, pseudodiploidy as having 45-46 chromosomes in a cell, and near-tetraploid karyotype originates from doubling of the hypodiploid and pseudodiploid karyotypes (>75 chromosomes) [42]. Hypodiploidy was an important independent factor for worse overall survival in multivariate analysis that included Durie and Salmon stage, treatment or bone marrow plasmocytosis [43]. In the non-hyperdiploid population, hypodiploid cases are associated with a higher prevalence of genetic alterations and a worse prognosis [42].

\section{IGH translocations}

IGH translocations, with a breakpoint on chromosome 14 band $q 32$, are often present in tumours of the lymphoid lineage due to the common physiological DNA rearrangements at the immunoglobulin heavy chain (IGH) locus that might have been displayed incorrectly [44]. The aberration in IGH in MM occurs mostly during class switching, and the juxtaposition of an oncogene next to the IGH locus results in overexpression of the affected oncogene [45]. In MM, the IGH translocations occur in up to $60 \%$ of patients $[15,46]$. There are five main translocation partner chromosomes including the $\mathrm{t}(4 ; 14)$ (p16;q32) - multiple myeloma set domain (MMSET), $t(6 ; 14)$ (p21;q32) - cyclin D3 gene, t(11;14)(q13;q32) - cyclin D1 gene, $t(14 ; 16)(q 32 ; q 23)$ - musculoaponeurotic fibrosarcoma (C-MAF), and t(14;20)(q32;q12) - musculoaponeurotic fibrosarcoma oncology family, protein B (MAFB) [45]. Moreover, the recurrent IGH translocations (mostly with partner chromosomes 11, 4, and 16) are highly associated with nonhyperdiploid karyotype [47].

\section{$\mathrm{t}(4 ; 14)(\mathrm{p} 16 ; \mathrm{q} 32)$}

Translocation $\mathrm{t}(4 ; 14)$, present in $10-15 \%$ of newly diagnosed cases, is not detectable by conventional karyotyping $[25,48,49]$. It is associated with poor prognosis and is considered to be a high-risk prognostic factor $[48,49]$. Translocation $\mathrm{t}(4 ; 14)$ is associated with immature morphology, higher tumour mass, and more frequent chromosome 13 abnormalities [50]. It is also reported to be less frequently associated with bone lesions, which consequently might be associated with delayed diagnosis [51]. Patients with $t(4 ; 14)$ seem to benefit from bortezomib-based therapy and bortezomib maintenance, and lenalidomide maintenance also might provide better survival in this group of patients $[52,53,54]$. It is also recommended to implement autologous stem cell transplantation (ASCT) as soon as possible in this cytogenetic subtype, and tandem ASCT should be considered [5]. Moreover, data from the MM-003 trial shows that pomalidomide plus low-dose dexamethasone is an effective strategy in relapsed/refractory settings in patients with $\mathrm{t}(4 ; 14)$ [55].

\section{$\mathrm{t}(11 ; 14)(\mathrm{q13} ; \mathrm{q32})$}

The most common IGH translocation, accounting for 15$-20 \%$ of cases, is $\mathrm{t}(11 ; 14)[48,49,56]$. This translocation results in upregulation and overexpression of the cyclin D1 that might be detected by immunohistochemistry [57]. Translocation $\mathrm{t}(11 ; 14)$ is more prevalent in plasma cell leukemia patients as well as in light chain amyloidosis patients than in MM patients [58, 59,60]. Although the prognostic impact is considered to be standard, some studies suggest that the overall survival and response rates are inferior to other standard risk patients [61, 62]. Translocation $\mathrm{t}(11 ; 14)$ is more frequent among the African-American population and exerts negative influence on the survival in African-Americans compared to non-African-Americans [63, 64]. It is associated with lymphoplasmacytic morphology and frequently with low serum monoclonal protein or nonsecretory $\mathrm{MM}$, and it is also less likely to coexist with hyperdiploid karyotype $[50,57]$. In $t(11 ; 14)$ the expression of $C D 20$ is often present [65]. The Mayo Clinic experts recommend the use of combined bortezomib and lenalidomide regimens followed by early ASCT and lenalidomide maintenance in $t(11 ; 14)$ patients [5]. The $t(11 ; 14)$ is associated with high expression of BCL2 protein and several studies have suggested the efficacy of the use of venetoclax, the BCL2 inhibitor, in $\mathrm{t}(11 ; 14)$ positive patients. 


\section{$\mathrm{t}(14 ; 16)(\mathrm{q} 32 ; \mathrm{q} 23)$}

The more common MAF translocation, $\mathrm{t}(14 ; 16)$, present in $2-5 \%$ of newly diagnosed cases, is hardly detectable by conventional karyotyping $[25,49,56]$. Translocation $t(14 ; 16)$ is associated with adverse outcomes, even in the era of novel drugs, something recently confirmed by a large international sample study conducted by our group $[49,66$, 67]. Renal failure as a MDE is more frequently observed in patients with $t(14 ; 16)$ than in other cytogenetic subtypes. It is associated with high levels of free light chain in serum, which might partially explain the poorer prognosis in $t(14 ; 16)$ positive group of patients $[51,68]$. It has been observed that $\mathrm{t}(14 ; 16)$ is associated with negativity in CD56 expression and high proliferative activity, which might predispose toward an adverse outcome [69]. According to the Mayo Clinic experts, the treatment approach should be similar as in $\mathrm{t}(4 ; 14)$, and in patients with renal failure it is recommended to combine bortezomib with cyclophosphamide, thalidomide or adriamycin over lenalidomide [5]. Our study suggests that at least a three-drug induction regimen (including IMID and PI) should be used, ASCT should be performed wherever possible [67, 68], and tandem ASCT should be considered [5]. Maintenance should be based on bortezomib [5].

\section{$\mathrm{t}(14 ; 20)(\mathrm{q} 32 ; \mathrm{q1})$}

The second MAF translocation, $\mathrm{t}(14 ; 20)$, has a low prevalence, $1 \%$, and also exhibits adverse impact on outcomes, comparable to $t(14 ; 16)[56,70,71]$. Translocation $t(14 ; 20)$ is also associated with higher frequency of renal failure due to high levels of free light chains in serum [51, 68]. Treatment based on PI should be used in an induction therapy [68]. Double ASCT should be considered as an upfront treatment strategy in this group of patients [70], and maintenance should include bortezomib [5].

\section{Secondary cytogenetic abnormalities MYC translocation}

MYC translocations are secondary events and occur at late stages of tumour progression. They are present in $15-20 \%$ of patients [48, 72]. Most MYC translocations involve IGH locus, however other genes might be also involved (IGL, IGK, FAM46C, FOXO3 or BMP6) [56]. As a result of the juxtaposition, the expression of C-MYC is increased [73]. The impact of MYC translocation on survival is believed to be negative, although it is still a matter of debate $[73,74]$. It has been suggested that the negative impact on outcome of MYC is restricted to hyperdiploid MM and is caused by an interaction between $\mathrm{t}(\mathrm{MYC})$ and gain of 1q21 [72].

\section{9 gain}

19 gain is one of the most common aberrations in MM, present in approximately $30 \%$ of patients [75]. It is associated with end-organ damage and a higher tumour burden
[75]. It has been shown that $1 \mathrm{q}$ gain is associated with the evolution from MGUS to MM, and the copy number of the 1q gain increases with disease progression [76]. Although the prognostic impact is a contentious issue, recent studies suggest that $1 \mathrm{q}$ gain has a strong, independent negative impact on survival, even in the era of modern drugs and ASCT $[75,77]$. Although neither IMID- and PI-based treatment regimens nor ASCT seem to prolong survival in patients with 1q gain, a recent Mayo Clinic study suggested that Pl-based strategies might show a slightly better effect on outcomes [75]. Nonetheless, another study showed that with increasing number of copies of $1 \mathrm{q}$ gain, bortezomib resistance also increases [78].

\section{$1 p$ deletion}

$1 p$ deletion is present in approximately $20 \%$ of patients and has an adverse impact on outcomes [79, 80]. These patients might need more intensive treatment, similar to that for other high-risk MM subtypes $[5,80]$.

\section{$13 q$ deletion}

$13 q$ deletion is present in $45-50 \%$ of patients with $\mathrm{MM}$ [48]. The 13q deletion often coexists with other cytogenetic abnormalities, and the presence and time of occurrence of $13 q$ deletion depends on the presence of specific concurrent abnormalities [81]. 13q deletion detected by conventional karyotyping appears to predict poor outcomes (present in $10-15 \%$ of newly diagnosed patients) [82]. It has been shown that bortezomib might overcome the adverse impact of $13 q$ deletion [83].

\section{$17 p$ deletion}

$17 p$ deletion (associated with loss of the TP53 gene) is present in $10 \%$ of newly diagnosed patients, and the incidence increases with disease progression $[48,56]$. It is present in the majority of cases of plasma cell leukemia [84]. $17 p$ deletion is considered to be the most detrimental prognostic factor of high-risk disease and a poor outcome $[66,71]$. The size of clone carrying the abnormality seems to be significant for the prognosis, although a recent study found contradictory results [85]. The bi-allelic inactivation of TP53 has an additional negative impact on survival [86]. TP53 deletions are associated with more aggressive disease course and complications including plasmocytomas and hypercalcemia [49]. The studies on the influence of different treatment strategies are inconsistent. BMT CTN 0702 trial results showed no survival benefit of either tandem ASCT or intensive treatment that included ASCT with a subsequent four cycles of bortezomib and lenalidomide followed by lenalidomide maintenance in patients with $17 p$ deletion [87]. Moreover, Lakshman et al. showed that a deletion 17p positive patient did not benefit from IMID plus PI-based induction as well as early ASCT [85]. On the other hand, according 
to the recent study based on the EMN02/H095 trial, patients with $17 \mathrm{p}$ deletion were benefiting from intensive treatment including tandem ASCT and bortezomib-based induction therapy [88].

Despite all these differences, recommendations suggest using induction therapy based on IMIDs and PI (bortezomib or carfilzomib) and subsequently considering tandem ASCT and prolonged bortezomib maintenance [71, 89]. Of note, pomalidomide seems to be particularly active in $17 p$ deletion [90].

\section{Specific mutations}

In recent years, the genomic landscape of MM has been thoroughly studied, and several recurrent mutations identified, most of them involving genes implicated in the translocation of chromosome 14 or MAPK pathway, critical in cell growth and survival [91]. Some of them are related to the cytogenetic MM subtype, e.g. FGFR3 or PRKD2 genes mutations occur mainly in $\mathrm{t}(4 ; 14)$ positive patients; CCND1, KRAS and IRF4 genes mutations are detected in $t(11 ; 14)$ positive patients or TP53 gene mutation is present in 17p deletion positive patients [5]. The MAPK genes mutations are represented by KRAS and NRAS, present in $40 \%$ of patients as well as BRAF genes mutations present in approximately $4 \%$ of patients [92]. Patients with mutations in NRAS or KRAS have worse survival than those with wild-type RAS genes [93]. It has been shown that patients with NRAS mutation exhibit reduced sensitivity to bortezomib [94]. For the MAP kinase pathway, several mutation-specific drugs are tested, e.g. vemurafenib in BRAF positive tumours or trametinib in AKT mutation [5].

\section{Double/triple hit MM}

High risk cytogenetic aberrations, especially secondary genetic aberration events, often overlap. For example, in a study by Boyd et al. in a group of patients with adverse IGH translocation [t(4;14), $\mathrm{t}(14 ; 16)$ or $\mathrm{t}(14 ; 20)]$, almost $72 \%$ had additionally $1 q$ gain, and $12.4 \%$ had $17 p$ deletion [95]. To address the prognosis of patients with multiple adverse cytogenetic aberrations, the mSMART classification includes the concepts of 'double hit' (when any two high risk factors are present) and 'triple hit' (when any three high risk factors are present) as a high risk stage with poor prognosis (Table III) [7]. A recent study showed the predictive value of double- and triple-hit MM, with double-hit MM having OS of 6 months vs. 32 months for patients with one high risk factor, and 57 months for patients with no high risk factor [96].

\section{Staging approaches}

The most universally accepted staging systems are set out in Table III. The Mayo Clinic recommends both conventional cytogenetic and FISH tests, and FISH is preferred if both are not available. All patients should be stratified and classified into standard- or high-risk groups using the mSMART criteria (Table III) and the FISH set should include detecting at least $\mathrm{t}(11 ; 14), \mathrm{t}(4 ; 14), \mathrm{t}(14 ; 16), \mathrm{t}(6 ; 14), \mathrm{t}(14 ; 20)$, trisomies, and $17 p$ deletion $[71,97]$. The EMN recommends performing FISH after $\mathrm{CD} 138^{+}$plasma cell enrichment, and the analysis should include at least $t(4 ; 14)$ and $17 p$ deletion; analysis of $t(14 ; 16), 1 q$ gain and $1 p$ deletion [98]. The National Comprehensive Cancer Network (NCCN) recommends FISH panel on bone marrow which includes 13 deletion, $17 p$ deletion, $t(4 ; 14), t(11 ; 14), t(14 ; 16), t(14: 20), 1 q$ amplification and $1 p$ deletion as an initial work-up [99]. According to the IMWG, the essential testing should include either clg-FISH or FISH carried out on the nuclei from purified plasma cells. The minimum panel required for prognostic estimation should include $t(4 ; 14), t(14 ; 16)$ and $17 p$ deletions. A more comprehensive panel should include testing for $\mathrm{t}(11 ; 14), 13$ deletion, ploidy category and chromosome 1 abnormalities [100]. The Polish guidelines for the basic evaluation of cytogenetic prognosis suggest stepwise FISH testing: the first step includes TP53 gene and IGH gene. If the IGH rearrangement is present, gene FGFR3/t $(4 ; 14)$ should be verified. If there is no FGFR3 fusion, further analysis should include MAF/t $(14 ; 16)$ gene status. Extended testing should include additionally $t(14 ; 16), t(14 ; 20)$, chromosome 1 status, $\mathrm{t}(11 ; 14)$, MYC rearrangement, 13 deletion and the 5, 9 and 15 chromosome aberrations. Karyotyping is an optional study according to the Polish experts' recommendations [101].

It should be highlighted that the risk factors described for newly diagnosed patients might be applicable to the relapse or refractory setting. However, in that case, other factors seem to be equally crucial. For example, the resistance to primary treatment (primary refractory patients), or a short response after first line treatment with ASCT have poor prognosis, even if other high risk factors were not detected $[102,103]$. Another powerful predictor of outcome in MM is MRD status after induction treatment, and its negativity predicts better survival [104]. Although not routinely monitored, MRD has a growing significance in monitoring the disease in clinical trials. MRD can be monitored by multiparameter flow cytometry or using molecular techniques like polymerase chain reaction (PCR) or NGS on a bone marrow sample. Studies evaluating NGS in MRD have shown that its negativity surpasses the traditional complete remission criterium in predicting better outcomes in MM patients [105, 106], and its sensitivity reaches $10^{-6}$ [107]. Limitations in utilising NGS in MRD monitoring include lack of standardisation, low availability, and frequent haemodilution of the bone marrow sample [98].

\section{Conclusions}

$\mathrm{MM}$ is a highly heterogenous, gnomically evolving and ever-changing disease, with no disease-identifying unique 
molecular aberration. The coexisting numerous subclones and potential lack of functionality of some mutations make interpretation even more difficult. Nonetheless, based on the cytogenetic and molecular landscape, several different subtypes of MM have been identified with different clinical characteristics and prognosis, and clinical decisions regarding treatment should be made based on the cytogenetic results. The establishment of individualised and cytogenetic subtype- or mutation-targeted treatment strategies are of the utmost importance in future studies.

\section{Authors' contributions}

SGM - wrote manuscript; DHV, AJ - critically revised manuscript.

\section{Conflict of interest}

None.

\section{Financial support}

None.

\section{Ethics}

The work described in this article has been carried out in accordance with The Code of Ethics of the World Medical Association (Declaration of Helsinki) for experiments involving humans; EU Directive 2010/63/EU for animal experiments; Uniform requirements for manuscripts submitted to biomedical journals.

\section{References}

1. Kyle RA, Therneau T, Rajkumar S, et al. Incidence of multiple myeloma in Olmsted County, Minnesota. Cancer. 2004; 101(11): 2667-2674, doi: 10.1002/cncr.20652.

2. Howell DA, Smith AG, Jack A, et al. Incidence of haematological malignancy by sub-type: a report from the Haematological Malignancy Research Network. Br J Cancer. 2011; 105(11): 1684-1692, doi: 10.1038/bjc.2011.450, indexed in Pubmed: 22045184.

3. Tsang M, Le M, Ghazawi FM, et al. Multiple myeloma epidemiology and patient geographic distribution in Canada: a population study. Cancer. 2019; 125(14): 2435-2444, doi: 10.1002/cncr.32128, indexed in Pubmed: 30951209.

4. Therneau TM, Kyle RA, Melton $\sqcup$, et al. Incidence of monoclonal gammopathy of undetermined significance and estimation of duration before first clinical recognition. Mayo Clin Proc. 2012; 87(11): 1071-1079, doi: 10.1016/j.mayocp.2012.06.014, indexed in Pubmed: 22883742.

5. KumarSK, RajkumarSV. The multiple myelomas-currentconcepts in cytogenetic classification and therapy. Nat Rev Clin Oncol. 2018; 15(7): 409-421, doi: 10.1038/s41571-018-0018-y, indexed in Pubmed: 29686421.

6. Kyle RA, Gertz MA, Witzig TE, et al. Review of 1027 patients with newly diagnosed multiple myeloma. Mayo Clin Proc. 2003; 78(1): 21-33, doi: $10.4065 / 78.1 .21$, indexed in Pubmed: 12528874.

7. Rajkumar SV. Multiple myeloma: 2020 update on diagnosis, risk-stratification and management. Am J Hematol. 2020; 95(5): 548-567, doi: 10.1002/ajh.25791, indexed in Pubmed: 32212178.
8. Robiou du Pont S, Cleynen A, Fontan C, et al. Genomics of multiple myeloma. J Clin Oncol. 2017; 35(9): 963-967, doi: 10.1200/ /JC0.2016.70.6705, indexed in Pubmed: 28297630.

9. Durie BGM, Hoering A, Abidi MH, et al. Bortezomib with lenalidomide and dexamethasone versus lenalidomide and dexamethasone alone in patients with newly diagnosed myeloma without intent for immediate autologous stem-cell transplant (SWOG S0777): a randomised, open-label, phase 3 trial. Lancet. 2017; 389(10068): 519-527, doi: 10.1016/S0140-6736(16)31594-X, indexed in Pubmed: 28017406.

10. Hanbali A, Hassanein M, Rasheed W, et al. The evolution of prognostic factors in multiple myeloma. Adv Hematol. 2017; 2017: 4812637, doi: 10.1155/2017/4812637, indexed in Pubmed: 28321258.

11. Corre J, Munshi N, Avet-Loiseau H. Genetics of multiple myeloma: another heterogeneity level? Blood. 2015; 125(12): 1870-1876, doi: 10.1182/blood-2014-10-567370, indexed in Pubmed: 25628468.

12. Corre J, Cleynen A, Robiou du Pont S, et al. Multiple myeloma clonal evolution in homogeneously treated patients. Leukemia. 2018; 32(12): 2636-2647, doi: 10.1038/s41375-018-0153-6, indexed in Pubmed: 29895955.

13. Merz M, Hielscher T, Schult D, et al. Cytogenetic subclone formation and evolution in progressive smoldering multiple myeloma. Leukemia. 2020; 34(4): 1192-1196, doi: 10.1038/s41375-019-0634-2, indexed in Pubmed: 31712777.

14. Rajan AM, Rajkumar SV. Interpretation of cytogenetic results in multiple myeloma for clinical practice. Blood Cancer J. 2015; 5: e365, doi: 10.1038/bcj.2015.92, indexed in Pubmed: 26517360.

15. Bergsagel PL, Nardini E, Brents L, et al. Promiscuous translocations into immunoglobulin heavy chain switch regions in multiple myeloma. Proc Natl Acad Sci USA. 1996; 93(24): 13931-13936, doi: 10.1073/ /pnas.93.24.13931, indexed in Pubmed: 8943038.

16. Rajkumar SV. Prevention of progression in monoclonal gammopathy of undetermined significance. Clin Cancer Res. 2009; 15(18): 5606-5608, doi: 10.1158/1078-0432.CCR-09-1575, indexed in Pubmed: 19737944.

17. Rajkumar SV, Fonseca R, Dewald GW, et al. Cytogenetic abnormalities correlate with the plasma cell labeling index and extent of bone marrow involvement in myeloma. Cancer Genet Cytogenet. 1999; 113(1): 73-77, doi: 10.1016/s0165-4608(99)00009-6, indexed in Pubmed: 10459351.

18. Avet-Loiseau H, Daviet A, Brigaudeau C, et al. Cytogenetic, interphase, and multicolor fluorescence in situ hybridization analyses in primary plasma cell leukemia: a study of 40 patients at diagnosis, on behalf of the Intergroupe Francophone du Myélome and the Groupe Français de Cytogénétique Hématologique. Blood. 2001; 97(3): 822-825, doi: 10.1182/blood.v97.3.822, indexed in Pubmed: 11157506.

19. Soekojo CY, Wang GM, Chen Y, et al. Role of conventional karyotyping in multiple myeloma in the era of modern treatment and FISH anaIysis. Clin Lymphoma Myeloma Leuk. 2019; 19(8): e470-e477, doi: 10.1016/j.clml.2019.04.011, indexed in Pubmed: 31171473.

20. Kapoor P, Fonseca R, Rajkumar SV, et al. Evidence for cytogenetic and fluorescence in situ hybridization risk stratification of newly diagnosed multiple myeloma in the era of novel therapie. Mayo Clin Proc. 2010; 85(6): 532-537, doi: 10.4065/mcp.2009.0677, indexed in Pubmed: 20511484.

21. Tian E. Fluorescence in situ hybridization (FISH) in multiple myeloma. Methods Mol Biol. 2018; 1792: 55-69, doi: 10.1007/978-1-49397865-6_5, indexed in Pubmed: 29797252.

22. Fonseca R, Barlogie B, Bataille R, et al. Genetics and cytogenetics of multiple myeloma: a workshop report. Cancer Res. 2004; 64(4): 1546-1558, doi: 10.1158/0008-5472.can-03-2876, indexed in Pubmed: 14989251. 
23. Ross FM, Avet-Loiseau H, Ameye G, et al. European Myeloma Network. Report from the European Myeloma Network on interphase FISH in multiple myeloma and related disorders. Haematologica. 2012; 97(8): 1272-1277, doi: 10.3324/haematol.2011.056176, indexed in Pubmed: 22371180.

24. Hartmann L, Biggerstaff JS, Chapman DB, et al. Detection of genomic abnormalities in multiple myeloma: the application of FISH analysis in combination with various plasma cell enrichment techniques. Am J Clin Pathol. 2011; 136(5): 712-720, doi: 10.1309/AJCPF7NFLW8UAJEP, indexed in Pubmed: 22031309.

25. Saxe D, Seo EJ, Bergeron MB, et al. Recent advances in cytogenetic characterization of multiple myeloma. Int J Lab Hematol. 2019; 41(1): 5-14, doi: 10.1111/ijlh.12882, indexed in Pubmed: 29971938.

26. An G, Li Z, Tai YT, et al. The impact of clone size on the prognostic value of chromosome aberrations by fluorescence in situ hybridization in multiple myeloma. Clin Cancer Res. 2015; 21(9): 2148-2156, doi: 10.1158/1078-0432.CCR-14-2576, indexed in Pubmed: 25652456.

27. Bolli N, Biancon G, Moarii M, et al. Analysis of the genomic landscape of multiple myeloma highlights novel prognostic markers and disease subgroups. Leukemia. 2018; 32(12): 2604-2616, doi: 10.1038/ /s41375-018-0037-9, indexed in Pubmed: 29789651.

28. Bolli N, Genuardi E, Ziccheddu B, et al. Next-generation sequencing for clinical management of multiple myeloma: ready for prime time? Front Oncol. 2020; 10: 189, doi: 10.3389/fonc.2020.00189, indexed in Pubmed: 32181154.

29. Hoang ML, Chen $\mathrm{CH}$, Sidorenko VS, et al. Mutational signature of aristolochic acid exposure as revealed by whole-exome sequencing. Sci TransI Med. 2013; 5(197): 197ra102, doi: 10.1126/scitranslmed.3006200, indexed in Pubmed: 23926200.

30. Samur MK, Aktas Samur A, Fulciniti M, et al. Genome-wide somatic alterations in multiple myeloma reveal a superior outcome group. J Clin Oncol. 2020; 38(27): 3107-3118, doi: 10.1200/JC0.20.00461, indexed in Pubmed: 32687451.

31. Sawyer JR. The prognostic significance of cytogenetics and molecular profiling in multiple myeloma. Cancer Genet. 2011; 204(1): 3-12, doi: 10.1016/j.cancergencyto.2010.11.002, indexed in Pubmed: 21356186.

32. Kuiper R, Broyl A, de Knegt $Y$, et al. A gene expression signature for high-risk multiple myeloma. Leukemia. 2012; 26(11): 2406-2413, doi: 10.1038/leu.2012.127, indexed in Pubmed: 22722715.

33. Kuiper R, van Duin M, van Vliet MH, et al. Prediction of high- and low-risk multiple myeloma based on gene expression and the International Staging System. Blood. 2015; 126(17): 1996-2004, doi: 10.1182/blood-2015-05-644039, indexed in Pubmed: 26330243.

34. Shaughnessy JD, Zhan F, Burington BE, et al. A validated gene expression model of high-risk multiple myeloma is defined by deregulated expression of genes mapping to chromosome 1. Blood. 2007; 109(6): 2276-2284, doi: 10.1182/blood-2006-07-038430, indexed in Pubmed: 17105813.

35. Smetana J, Frohlich J, Zaoralova R, et al. Genome-wide screening of cytogenetic abnormalities in multiple myeloma patients using array-CGH technique: a Czech multicenter experience. Biomed Res Int. 2014; 2014: 209670, doi: 10.1155/2014/209670, indexed in Pubmed: 24987674.

36. Avet-Loiseau H, Li C, Magrangeas F, et al. Prognostic significance of copy-number alterations in multiple myeloma. J Clin Oncol. 2009; 27(27): 4585-4590, doi: 10.1200/JC0.2008.20.6136, indexed in Pubmed: 19687334.

37. Kumar S, Fonseca R, Ketterling RP, et al. Trisomies in multiple myeloma: impact on survival in patients with high-risk cytogenetics. Blood. 2012; 119(9): 2100-2105, doi: 10.1182/blood-2011-11-390658, indexed in Pubmed: 22234687.
38. Chretien ML, Corre J, Lauwers-Cances V, et al. Understanding the role of hyperdiploidy in myeloma prognosis: which trisomies really matter? Blood. 2015; 126(25): 2713-2719, doi: 10.1182/ /blood-2015-06-650242, indexed in Pubmed: 26516228.

39. Vu T, Gonsalves W, Kumar S, et al. Characteristics of exceptional responders to lenalidomide-based therapy in multiple myeloma. Blood Cancer J. 2015; 5: e363, doi: 10.1038/bcj.2015.91, indexed in Pubmed: 26495860.

40. Pawlyn C, Melchor L, Murison A, et al. Coexistent hyperdiploidy does not abrogate poor prognosis in myeloma with adverse cytogenetics and may precede IGH translocations. Blood. 2015; 125(5): 831 -840, doi: 10.1182/blood-2014-07-584268, indexed in Pubmed: 25428216.

41. Carballo-Zarate AA, Medeiros L, Fang L, et al. Additional-structural-chromosomal aberrations are associated with inferior clinical outcome in patients with hyperdiploid multiple myeloma: a single-institution experience. Mod Pathol. 2017; 30(6): 843-853, doi: 10.1038/modpathol.2017.3, indexed in Pubmed: 28281554.

42. Van Wier S, Braggio E, Baker A, et al. Hypodiploid multiple myeloma is characterized by more aggressive molecular markers than non-hyperdiploid multiple myeloma. Haematologica. 2013; 98(10): 1586-1592, doi: 10.3324/haematol.2012.081083, indexed in Pubmed: 23716545.

43. Smadja NV, Bastard C, Brigaudeau C, et al. Groupe Français de Cytogénétique Hématologique. Hypodiploidy is a major prognostic factor in multiple myeloma. Blood. 2001; 98(7): 2229-2238, doi: 10.1182/ /blood.v98.7.2229, indexed in Pubmed: 11568011.

44. Walker BA, Wardell CP, Johnson DC, et al. Characterization of IGH locus breakpoints in multiple myeloma indicates a subset of translocations appear to occur in pregerminal center B cells. Blood. 2013; 121(17): 3413-3419, doi: 10.1182/blood-2012-12-471888, indexed in Pubmed: 23435460.

45. Morgan GJ, Walker BA, Davies FE. The genetic architecture of multiple myeloma. Nat Rev Cancer. 2012; 12(5): 335-348, doi: 10.1038/ /nrc3257, indexed in Pubmed: 22495321.

46. Pratt G, Fenton JA, Proffitt JA, et al. True spectrum of $14 q 32$ translocations in multiple myeloma. Br J Haematol. 1998; 103(4): 1209-1210, doi: 10.1046/j.1365-2141.1998.1161d.x, indexed in Pubmed: 9886346.

47. Fonseca R, Debes-Marun CS, Picken EB, et al. The recurrent IgH translocations are highly associated with nonhyperdiploid variant multiple myeloma. Blood. 2003; 102(7): 2562-2567, doi: 10.1182/ /blood-2003-02-0493, indexed in Pubmed: 12805059.

48. Avet-Loiseau H, Hulin C, Campion L, et al. Genetic abnormalities and survival in multiple myeloma: the experience of the Intergroupe Francophone du Myélome. Blood. 2007; 109(8): 3489-3495, doi: 10.1182/blood-2006-08-040410, indexed in Pubmed: 17209057.

49. Fonseca R, Blood E, Rue M, et al. Clinical and biologic implications of recurrent genomic aberrations in myeloma. Blood. 2003; 101(11): 4569-4575, doi: 10.1182/blood-2002-10-3017, indexed in Pubmed: 12576322 .

50. Garand R, Avet-Loiseau H, Accard F, et al. t(11;14) and t(4;14) translocations correlated with mature lymphoplasmacytoid and immature morphology, respectively, in multiple myeloma. Leukemia. 2003; 17(10): 2032-2035, doi: 10.1038/sj.leu.2403091, indexed in Pubmed: 14513054.

51. Greenberg AJ, Rajkumar SV, Therneau TM, et al. Relationship between initial clinical presentation and the molecular cytogenetic classification of myeloma. Leukemia. 2014; 28(2): 398-403, doi: 10.1038/ /leu.2013.258, indexed in Pubmed: 24005246. 
52. Avet-Loiseau H, Leleu X, Roussel M, et al. Bortezomib plus dexamethasone induction improves outcome of patients with $t(4 ; 14)$ myeloma but not outcome of patients with del(17p). J Clin Oncol. 2010; 28(30): 4630-4634, doi: 10.1200/JC0.2010.28.3945, indexed in Pubmed: 20644101.

53. El-Ghammaz AMS, Abdelwahed E. Bortezomib-based induction improves progression-free survival of myeloma patients harboring $17 \mathrm{p}$ deletion and/or $\mathrm{t}(4 ; 14)$ and overcomes their adverse prognosis. Ann Hematol. 2016; 95(8): 1315-1321, doi: 10.1007/s00277-016-2692-0, indexed in Pubmed: 27184486.

54. Jackson GH, Davies FE, Pawlyn C, et al. UK NCRI Haemato-oncology Clinical Studies Group. Lenalidomide maintenance versus observation for patients with newly diagnosed multiple myeloma (Myeloma XI): a multicentre, open-label, randomised, phase 3 trial. Lancet Oncol. 2019; 20(1): 57-73, doi: 10.1016/S1470-2045(18)30687-9, indexed in Pubmed: 30559051.

55. Yan X, Xu XuS, Weisel KC, et al. Impact of prior treatment and depth of response on survival in MM-003, a randomized phase 3 study comparing pomalidomide plus low-dose dexamethasone versus high-dose dexamethasone in relapsed/refractory multiple myeloma. Haematologica. 2015; 100(10): 1334-1339, doi: 10.3324/haematol.2015.125864, indexed in Pubmed: 26160879.

56. Walker BA, Wardell CP, Murison A, et al. APOBEC family mutational signatures are associated with poor prognosis translocations in multiple myeloma. Nat Commun. 2015; 6: 6997, doi: 10.1038/ncomms7997, indexed in Pubmed: 25904160.

57. Fonseca R, Blood EA, Oken MM, et al. Myeloma and the $t(11 ; 14)$ (q13;q32); evidence for a biologically defined unique subset of patients. Blood. 2002; 99(10): 3735-3741, doi: 10.1182/blood. v99.10.3735, indexed in Pubmed: 11986230.

58. Kobayashi A, Misumida N, Aoi S, et al. Prevalence and clinical implication of Wellens' sign in patients with non-ST-segment elevation myocardial infarction. Cardiol Res. 2019; 10(3): 135-141, doi: 10.14740/cr856, indexed in Pubmed: 31236175.

59. Royer B, Minvielle S, Diouf M, et al. Bortezomib, doxorubicin, cyclophosphamide, dexamethasone induction followed by stem cell transplantation for primary plasma cell leukemia: a prospective phase II study of the Intergroupe Francophone du Myélome. J Clin Oncol. 2016; 34(18): $2125-$ -2132, doi: 10.1200/JC0.2015.63.1929, indexed in Pubmed: 27114594.

60. Jurczyszyn A, Radocha J, Davila J, et al. Prognostic indicators in primary plasma cell leukaemia: a multicentre retrospective study of 117 patients. Br J Haematol. 2018; 180(6): 831-839, doi: 10.1111/ /bjh.15092, indexed in Pubmed: 29315478.

61. Sasaki K, Lu G, Saliba RM, et al. Impact of $t(11 ; 14)(q 13 ; q 32)$ on the outcome of autologous hematopoietic cell transplantation in multiple myeloma. Biol Blood Marrow Transplant. 2013; 19(8): 1227-1232, doi: 10.1016/j.bbmt.2013.05.017, indexed in Pubmed: 23733001.

62. Lakshman A, Alhaj Moustafa M, Rajkumar SV, et al. Natural history of t(11;14) multiple myeloma. Leukemia. 2018; 32(1): 131-138, doi: 10.1038/leu.2017.204, indexed in Pubmed: 28655925.

63. Gasparetto C, Abonour R, Jagannath S, et al. Impact of $t(11 ; 14)$ on outcomes in African American (AA) and non-AA (NAA) patients (Pts) with newly diagnosed multiple myeloma (NDMM): connect MM registry. J Clin Oncol. 2017; 35(15_Suppl): 8023, doi: 10.1200/ /JC0.2017.35.15_SUPPL.8023, indexed in Pubmed: 57526931.

64. Kazandjian D, Hill E, Hultcrantz M, et al. Molecular underpinnings of clinical disparity patterns in African American vs. Caucasian American multiple myeloma patients. Blood Cancer J. 2019; 9(2): 15, doi: 10.1038/s41408-019-0177-9, indexed in Pubmed: 30718460.
65. Robillard N, Avet-Loiseau H, Garand R, et al. CD20 is associated with a small mature plasma cell morphology and $t(11 ; 14)$ in multiple myeloma. Blood. 2003; 102(3): 1070-1071, doi: 10.1182/ /blood-2002-11-3333, indexed in Pubmed: 12702507.

66. Palumbo A, Avet-Loiseau H, Oliva S, et al. Revised International Staging System for Multiple Myeloma: a report from International MyeIoma Working Group. J Clin Oncol. 2015; 33(26): 2863-2869, doi: 10.1200/JC0.2015.61.2267, indexed in Pubmed: 26240224.

67. Goldman-Mazur S, Jurczyszyn A, Castillo J, et al. A multicenter retrospective study of 223 patients with $t(14 ; 16)$ in multiple myeloma. Am J Hematol. 2020; 95(5): 503-509, doi: 10.1002/ajh.25758.

68. Abdallah N, Rajkumar SV, Greipp P, et al. Cytogenetic abnormalities in multiple myeloma: association with disease characteristics and treatment response. Blood Cancer J. 2020; 10(8): 82, doi: 10.1038/ /s41408-020-00348-5, indexed in Pubmed: 32782240.

69. Narita T, Inagaki A, Kobayashi T, et al. t(14;16)-positive multiple myeloma shows negativity for CD56 expression and unfavorable outcome even in the era of novel drugs. Blood Cancer J. 2015; 5: e285.

70. Goldman-Mazur S, Jurczyszyn A, Castillo JJ, et al. Different MAF translocations confer similar prognosis in newly diagnosed multiple myeloma patients. Leuk Lymphoma. 2020; 61(8): 1885-1893, doi: 10.1080/10428194.2020.1749605, indexed in Pubmed: 32306794.

71. Mikhael JR, Dingli D, Roy V, et al. Mayo Clinic. Management of newly diagnosed symptomatic multiple myeloma: updated Mayo Stratification of Myeloma and Risk-Adapted Therapy (mSMART) consensus guidelines 2013. Mayo Clin Proc. 2013; 88(4): 360-376, doi: 10.1016/j. mayocp.2013.01.019, indexed in Pubmed: 23541011.

72. Weinhold N, Kirn D, Seckinger A, et al. Concomitant gain of $1 q 21$ and MYC translocation define a poor prognostic subgroup of hyperdiploid multiple myeloma. Haematologica. 2016; 101(3): e116-e119, doi: 10.3324/haematol.2015.136929, indexed in Pubmed: 26611471.

73. Dib A, Gabrea A, Glebov OK, et al. Characterization of MYC translocations in multiple myeloma cell lines. J Natl Cancer Inst Monogr. 2008(39): 25-31, doi: 10.1093/jncimonographs/lgn011, indexed in Pubmed: 18647998.

74. Chesi M, Bergsagel PL. Advances in the pathogenesis and diagnosis of multiple myeloma. Int J Lab Hematol. 2015; 37(Suppl 1): 108-114.

75. Abdallah N, Greipp P, Kapoor P, et al. Clinical characteristics and treatment outcomes of newly diagnosed multiple myeloma with chromosome 1q abnormalities. Blood Adv. 2020; 4(15): 3509-3519, doi: 10.1182/ /bloodadvances.2020002218, indexed in Pubmed: 32750129.

76. Hanamura I, Stewart JP, Huang Y, et al. Frequent gain of chromosome band 1q21 in plasma-cell dyscrasias detected by fluorescence in situ hybridization: incidence increases from MGUS to relapsed myeloma and is related to prognosis and disease progression following tandem stem-cell transplantation. Blood. 2006; 108(5): 1724-1732, doi: 10.1182/blood-2006-03-009910, indexed in Pubmed: 16705089.

77. Giri S, Huntington SF, Wang R, et al. Chromosome 1 abnormalities and survival of patients with multiple myeloma in the era of novel agents. Blood Adv. 2020; 4(10): 2245-2253, doi: 10.1182/bloodadvances. 2019001425, indexed in Pubmed: 32442299.

78. An G, Xu Y, Shi L, et al. Chromosome 1q21 gains confer inferior outcomes in multiple myeloma treated with bortezomib but copy number variation and percentage of plasma cells involved have no additional prognostic value. Haematologica. 2014; 99(2): 353-359, doi: 10.3324/haematol.2013.088211, indexed in Pubmed: 24213147.

79. Hebraud B, Leleu X, Lauwers-Cances V, et al. Deletion of the $1 p 32$ region is a major independent prognostic factor in young patients with myeloma: the IFM experience on 1195 patients. Leukemia. 2014; 28(3): 675-679, doi: 10.1038/leu.2013.225, indexed in Pubmed: 23892719. 
80. Varma A, Sui D, Milton DR, et al. Outcome of multiple myeloma with chromosome 1q gain and $1 p$ deletion after autologous hematopoietic stem cell transplantation: propensity score matched analysis. Biol Blood Marrow Transplant. 2020; 26(4): 665-671, doi: 10.1016/j. bbmt.2019.12.726, indexed in Pubmed: 31881283.

81. Chiecchio L, Dagrada GP, Ibrahim AH, et al. UK Myeloma Forum. Timing of acquisition of deletion 13 in plasma cell dyscrasias is dependent on genetic context. Haematologica. 2009; 94(12): 1708-1713, doi: 10.3324/haematol.2009.011064, indexed in Pubmed: 19996118.

82. Chiecchio L, Protheroe RKM, Ibrahim AH, et al. Deletion of chromosome 13 detected by conventional cytogenetics is a critical prognostic factor in myeloma. Leukemia. 2006; 20(9): 1610-1617, doi: 10.1038/sj.leu.2404304, indexed in Pubmed: 16826223.

83. Jagannath S, Richardson PG, Sonneveld P, et al. Bortezomib appears to overcome the poor prognosis conferred by chromosome 13 deletion in phase 2 and 3 trials. Leukemia. 2007; 21(1): 151-157, doi: 10.1038/sj.leu.2404442, indexed in Pubmed: 17096017.

84. Tiedemann RE, Gonzalez-Paz N, Kyle RA, et al. Genetic aberrations and survival in plasma cell leukemia. Leukemia. 2008; 22(5): $1044-$ -1052, doi: 10.1038/leu.2008.4, indexed in Pubmed: 18216867.

85. Lakshman A, Painuly U, Rajkumar SV, et al. Natural history of multiple myeloma with de novo del(17p). Blood Cancer J. 2019; 9(3): 32, doi: 10.1038/s41408-019-0191-y, indexed in Pubmed: 30846679.

86. Thanendrarajan S, Tian E, Qu P, et al. The level of deletion $17 p$ and bi-allelic inactivation of has a significant impact on clinical outcome in multiple myeloma. Haematologica. 2017; 102(9): e364-e367, doi: 10.3324/haematol.2017.168872, indexed in Pubmed: 28550191.

87. Stadtmauer EA, Pasquini MC, Blackwell B, et al. Autologous transplantation, consolidation, and maintenance therapy in multiple myeloma: results of the BMT CTN 0702 trial. J Clin Oncol. 2019; 37(7): 589-597, doi: 10.1200/JC0.18.00685, indexed in Pubmed: 30653422.

88. Cavo M, Gay F, Beksac M, et al. Autologous haematopoietic stem-cell transplantation versus bortezomib-melphalan-prednisone, with or without bortezomib-lenalidomide-dexamethasone consolidation therapy, and lenalidomide maintenance for newly diagnosed multiple myeloma (EMN02/H095): a multicentre, randomised, open-label, phase 3 study. Lancet Haematol. 2020; 7(6): e456-e468, doi: 10.1016/S23523026(20)30099-5, indexed in Pubmed: 32359506.

89. Sonneveld P, Schmidt-Wolf IGH, van der Holt B, et al. Bortezomib induction and maintenance treatment in patients with newly diagnosed multiple myeloma: results of the randomized phase III HOVON-65/ /GMMG-HD4 trial. J Clin Oncol. 2012; 30(24): 2946-2955, doi: 10.1200/JC0.2011.39.6820, indexed in Pubmed: 22802322.

90. Leleu X, Karlin L, Macro M, et al. Intergroupe Francophone du Myélome (IFM). Pomalidomide plus low-dose dexamethasone in multiple myeloma with deletion 17p and/or translocation (4;14): IFM 201002 trial results. Blood. 2015; 125(9): 1411-1417, doi: 10.1182/ /blood-2014-11-612069, indexed in Pubmed: 25575538.

91. Pasca S, Tomuleasa C, Teodorescu P, et al. KRAS/NRAS/BRAF mutations as potential targets in multiple myeloma. Front Oncol. 2019; 9: 1137, doi: 10.3389/fonc.2019.01137, indexed in Pubmed: 31709194.

92. Andrulis M, Lehners N, Capper D, et al. Targeting the BRAF V600E mutation in multiple myeloma. Cancer Discov. 2013; 3(8): 862-869, doi: 10.1158/2159-8290.CD-13-0014, indexed in Pubmed: 23612012.

93. Liu P, Leong T, Quam L, et al. Activating mutations of $\mathrm{N}$ - and K-ras in multiple myeloma show different clinical associations: analysis of the Eastern Cooperative Oncology Group Phase III Trial. Blood. 1996; 88(7): 2699-2706, doi: 10.1182/blood.v88.7.2699.bloodjournal8872699.
94. Mulligan G, Lichter D, Bacco ADi, et al. Mutation of NRAS but not KRAS significantly reduces myeloma sensitivity to single-agent bortezomib therapy. Blood. 2014; 123(5): 632-639, doi: 10.1182/ /blood-2013-05-504340.

95. Boyd KD, Ross FM, Chiecchio L, et al. NCRI Haematology Oncology Studies Group. A novel prognostic model in myeloma based on co-segregating adverse FISH lesions and the ISS: analysis of patients treated in the MRC Myeloma IX trial. Leukemia. 2012; 26(2): 349-355, doi: 10.1038/leu.2011.204, indexed in Pubmed: 21836613.

96. Baysal M, Demirci U, Umit E, et al. Concepts of double hit and triple hit disease in multiple myeloma, entity and prognostic significance. Sci Rep. 2020; 10(1): 5991, doi: 10.1038/s41598-020-62885-0, indexed in Pubmed: 32249811.

97. Kumar SK, Mikhael JR, Buadi FK, et al. Management of newly diagnosed symptomatic multiple myeloma: updated Mayo Stratification of Myeloma and Risk-Adapted Therapy (mSMART) consensus guidelines. Mayo Clin Proc. 2009; 84(12): 1095-1110, doi: 10.4065/ /mcp.2009.0603, indexed in Pubmed: 19955246.

98. Caers Jo, Garderet L, Kortüm KM, et al. European Myeloma Network recommendations on tools for the diagnosis and monitoring of multiple myeloma: what to use and when. Haematologica. 2018; 103(11): 1772-1784, doi: 10.3324/haematol.2018.189159, indexed in Pubmed: 30171031.

99. Kumar SK, Callander NS, Hillengass J, et al. et al.. NCCN guidelines insights: multiple meloma, version 1.2020. J Natl Compr Canc Netw. 2019; 17(10): 1154-1165, doi: 10.6004/jnccn.2019.0049, indexed in Pubmed: 31590151.

100.Fonseca R, Bergsagel PL, Drach J, et al. International Myeloma Working Group. International Myeloma Working Group molecular classification of multiple myeloma: spotlight review. Leukemia. 2009; 23(12): 2210 -2221, doi: 10.1038/leu.2009.174, indexed in Pubmed: 19798094.

101. Giannopoulos KJK, Usnarska-Zubkiewicz L, Dytfeld D, et al. Recommendations of Polish Myeloma Group concerning diagnosis and therapy of multiple myeloma and other plasmacytic dyscrasias for 2018/2019. Acta Hematol Pol. 2018; 49(4): 157-206, doi: 10.2478/ahp-2018-0024.

102. Majithia N, Rajkumar SV, Lacy MQ, et al. Early relapse following initial therapy for multiple myeloma predicts poor outcomes in the era of novel agents. Leukemia. 2016; 30(11): 2208-2213, doi: 10.1038/ /leu.2016.147, indexed in Pubmed: 27211270.

103. Kumar SK, Dispenzieri A, Fraser R, et al. Early relapse after autologous hematopoietic cell transplantation remains a poor prognostic factor in multiple myeloma but outcomes have improved over time. Leukemia. 2018; 32(4): 986-995, doi: 10.1038/leu.2017.331, indexed in Pubmed: 29263438.

104. Romano A, Palumbo GA, Parrinello NL, et al. Minimal residual disease assessment within the bone marrow of multiple myeloma: a review of caveats, clinical significance and future perspectives. Front Oncol. 2019; 9: 699, doi: 10.3389/fonc.2019.00699, indexed in Pubmed: 31482061.

105. Chari A, Suvannasankha A, Fay JW, et al. Daratumumab plus pomalidomide and dexamethasone in relapsed and/or refractory multiple myeloma. Blood. 2017; 130(8): 974-981, doi: 10.1182/ /blood-2017-05-785246, indexed in Pubmed: 28637662.

106. Martinez-Lopez J, Lahuerta JJ, Pepin F, et al. Prognostic value of deep sequencing method for minimal residual disease detection in multiple myeloma. Blood. 2014; 123(20): 3073-3079, doi: 10.1182/ /blood-2014-01-550020, indexed in Pubmed: 24646471.

107. Perrot A, Lauwers-Cances V, Corre J, et al. Minimal residual disease negativity using deep sequencing is a major prognostic factor in multiple myeloma. Blood. 2018; 132(23): 2456-2464, doi: 10.1182/ /blood-2018-06-858613, indexed in Pubmed: 30249784. 